\title{
Research on Regional Cooperative Development of Chinese and Russian Colleges and Universities Based on Common Interests
}

\author{
Lili Qi \\ Heihe University \\ Heihe, China 164300
}

\begin{abstract}
In the context of the current economic globalization, international exchanges and cooperation among countries in the field of education are particularly important. With the deepening and expansion of international exchanges and cooperation in the field of education, to a certain extent, the process of economic internationalization has been greatly promoted. At present, Sino-Russian regional cooperation based on common interests involves all aspects. There are regional cooperation and common development strategic relations in many fields such as technology, economy, education and medical treatment. In recent years, the exchanged learning and academic forum between China and Russia have become more and more frequent. Focusing on the theme of regional cooperation and development in universities between China and Russia, this paper makes a comprehensive and in-depth discussion and analysis on Sino-Russian University cooperative development relationship based on common interests.
\end{abstract}

Keywords-Sino-Russian colleges and universities; common interests; regional cooperation

\section{INTRODUCTION}

On April 6, 2015, people from political, educational, and business circles in China and Russia gathered at the Russian State's Duma Golden Hall. The theme of this joint conference is to discuss and implement the specific issues of Sino-Russian joint universities in Shenzhen, China, and finally successfully signed the agreement on establishing the Legal Aid Center for Chinese students in Moscow State University, Russia. It can be said that the conference is a landmark in terms of University regional cooperation project between China and Russia in universities and education fields. Russia, as a neighbor of our country, has a strong educational base, because of its own level of development, including in the fields of economy, technology and education. At the same time, Russia is also one of the few developed countries as for higher education in the world. Its education level and university scale occupy a very important position in the world higher education field, and its influence on the neighboring countries is quite profound.

China and Russia have a good foundation and favorable political environment in terms of educational cooperation. Through the regional cooperation among universities in the two countries, they have continuously consolidated and developed this mutually beneficial strategic cooperative partnership, and they are constantly seeking for common interests between the two parties during the process of development. However, due to the large gap between the two countries in the areas of society, culture, education, ideology and so on, at present, the level of cooperation between China and Russia in running schools is relatively low, and there is a lack of scientific and effective control and management. Therefore, there are still some problems in the development of regional cooperation between Chinese and Russian universities based on common interests. Based on this condition, the author conducts research on the development of regional cooperation among universities between China and Russia, and seeks the cooperation purposes and premise of the two parties following the principle of common interest to identify gaps and achieve win-win development.

\section{HISTORY OF SINO-RUSSIAN EDUCATIONAL COOPERATION}

The development process of cooperation and exchanges in education between China and Russia is divided into three phases:

\section{A. The First Stage of Development}

This stage can be traced back to the 17th century. In 1689 , the Chinese and Russian governments jointly signed the "Nabhu Treaty." Since then, the two sides have begun to establish all aspects of development cooperation, especially in the field of education. Then, the Russian had been sending their students to our country for a long time. The Russian students learn the languages and cultures of Han, Manchu, Mongolian, Tibetan and other ethnic groups in China, and meanwhile, they learn the relative advanced medical skills of our country. At the time of 1708, the Qing government established the first Russian school in our country. During the next more than 100 years, the cooperation, exchange and study in the field of education between China and Russia were pretty frequent. 


\section{B. The Second Stage of Development}

I think this stage is within 20 years after the founding of New China. At that time, since the founding of new China, all aspects of the construction of the country were not perfect, especially in the field of economy, technology, culture and education. Due to the lack of some advanced scientific and cultural knowledge and advanced management experience in China's higher learning institutions, China had a frequent exchange with some Eastern European countries, including the former Soviet Union in the field of culture and education. In the meantime, our country devoted to transport foreign students continuously on a large scale to the former Soviet Union to strengthen the construction of the motherland. The cooperative development lasted more than ten years before the relationship deterioration between China and Soviet Union. From 1961 to 1965 , the number of mutually interchangeable students suffered great decrease. This awkward relationship didn't stop until the end of Cultural Revolution.

\section{The Third Stage of Development}

After the Cultural Revolution ended, China's cultural education experienced a bloody storm. Thanks for several years of development and improvement, the education system gradually recovered. In February 1982, the Ministry of Education of the former Soviet Union proposed to China for the restoration of cultural and educational exchanges between the two countries. In response, The Chinese government (Ministry of Education) sent a delegation to the Soviet Union (the former Soviet Union) in 1984. The heads of the two countries' education departments jointly signed a cooperation agreement on the universities for the 1984/1985 academic year with following 70 exchanged college students of the two sides, which indicates that the cultural education between China and the Soviet Union has returned to normal and the two sides have abandoned the former enmity to seek common development. At that time, the identified cooperative relations among the two countries' universities were as follows: Peking University-- Moscow State University; Tsinghua University-- Leningrad Institute of technology; Heilongjiang University--Irkutsk State University; Xinjiang University--Kazakh University; Beijing Institute of foreign languages - Pushkin College of Russian.

\section{THE PROBLEMS FACED BY CHINA AND RUSSIA IN THE AREA OF REGIONAL COOPERATION IN COLLEGES AND UNIVERSITIES}

\section{A. The Level of Joint School Running between China and Russia Is Not High}

The low level of cooperation in running a school is the main reason that why it is difficult to realize qualitative leap on China and Russia's higher education cooperation. Of course, this is also a phenomenon that prevails in both countries. On the basis of common interests, the two countries established regional cooperation-jointly running schools, which aims to achieve goals and practical significance as soon as possible, and there is still a certain degree of deficiency in the long-term goal development concept. Taking the current Sino--Russian joint education as an example, during the process of joint education, there was not much consideration for whether or not to adapt to China's basic national conditions when setting up and introducing cooperative specialties. Practice shows that most of the specialized courses set up in joint schools do not conform to the needs of China's basic national conditions. The introduction of teaching and educational resources is also not compatible with our science, culture and education construction and development. Meanwhile, many colleges and universities in China tend to choose the specialized courses of quick effect and less investment, which greatly reduces the level of Sino-Russian joint education.

\section{B. The Chinese and Russian People Lack the Necessary Mutual Recognition}

With the continuous transformation of the social and economic system, the field of spiritual culture and education has also changed. Coupled with the strong impact of the current western ideology and culture, people in China and Russia are all concerned about the western educational theory and educational practice. This leads to the gradual marginalization of higher education and scientific and cultural exchanges between China and Russia, which made Chinese and Russian people lack the corresponding sense of cognition for each other.

\section{Regional CoOperative DEVElopment of ChINESE AND RUSSIAN COLLEGES AND UNIVERSITIES BASED ON COMMON INTERESTS}

\section{A. The Regional Cooperative Between China and Russia Meets the Common Interests of Both Sides}

Generally, common interests refer to the interests of the community and the product of a certain interest relationship. The community can include a team, an organization, a community, a region, a country and even the whole human development society. We can see all of them as a community. Since the community is a development carrier of the real society, we can see that the interests of the members of the community exist in the community. So the common interests can also be called the "community of interests".

There are common interests in the development of regional cooperation between Chinese and Russian Universities and two sides are in the same interest community. It is necessary to achieve mutual benefits and seek further strategic development by establishing closer educational cooperation and exchange relationship. The common interest is the foundation of Sino-Russian regional cooperation. Only by emphasizing the common interests of both sides and achieving mutual benefit and win-win, can Sino-Russian regional cooperation be carried out smoothly.

\section{B. The Current Cooperation Between China and Russia in the Field of Higher Education Has A Solid Foundation.}

The foundation of the cooperation between China and Russia's higher institutions of higher education is solid. As mentioned before, China and Russia have deep historical 
origins in the field of education, cultural exchange and learning. Therefore, Sino-Russian educational cooperation is still pretty stable. After the disintegration of the former Soviet Union, a series of related documents of higher education cooperation were signed. And these documents contain quite extensive parts, including educational content, educational culture, and educational system and so on. On April 6, 2015, Chinese and Russian politicians and scholars gathered at the Russian State Duma Golden Conference Hall to discuss and sign the important agreement for the establishment of the Legal Aid Center for Chinese Students in Moscow, marking the further step of Chinese and Russian universities' regional cooperation and the further reinforcement and improvement of the comprehensive strategic partnership between China and Russia.

Under the tremendous impact of economic globalization and internationalization, the higher education in China is gradually integrated into the development trend in the era of educational internationalization. Against this background, the regional strategic development of university cooperation between China and Russia is developing to a higher level, which can be described by three stages: the initial exchange of overseas students, the later establishment of exchanges and cooperation relationship among universities in certain regions, and then, the buildup of current joint education.

Through the innovative mode of joint education, we should consolidate and deepen the educational cooperation between the two sides and seek the utmost interests of both parties. At present, there are already hundreds of colleges and universities in different levels in China that have established regional cooperation relationships with Russian related universities and colleges.

\section{The Development of Regional Cooperation and Exchange among Universities Between China and Russia Is Promising}

Economic globalization has provided China and Russia with vast space for educational cooperation. With the accelerating process of economic globalization and the continuous deepening and development of the multi-polar pattern of the world economy, the world today has entered an era of ever-growing economy and science and technology, and an era of fierce competitions for knowledge-based economy. There is a so-called concept that science and technology are the primary productive forces while talents are the core of the development of science and technology. Based on such a large environment, the desires and goals of each country in cultivating talents are also very strong. The inevitable trend of the development of higher education in all countries in the 21 st century is the internationalization, which is based on the influence and drive of the global economy, resulting that all areas, including education, are in the process of international development. The strengthening of educational cooperation and learning exchanges between China and Russia, and the establishment of close ties between universities in certain regions are inevitable choices for accelerating integration with international education in the context of current internationalization of higher education. Sino-Russian cooperation and exchange between universities in the region is also a requirement to adapt to the development of the times.

\section{COUNTERMEASURES TO PROMOTE THE DEVELOPMENT OF REGIONAL COOPERATION BETWEEN UNIVERSITIES IN CHINA AND RUSSIA}

On May 20, 2014, with the joint testimony of President $\mathrm{Xi}$ Jinping and President Putin, in Shanghai, China and Russia signed the " Memorandum of Understanding Signed by Ministry of Education of the People's Republic of China and the Ministry of Education and Science of the Russian Federation on the Construction of "Sino-China University" under the charge of Beijing Institute of Technology and Moscow State Lomonosov University " As stipulated in the memorandum, the two sides will support both colleges to run a school cooperatively, and provide policy guidance in accordance with their respective laws and regulations for the school. At present, the related work of the jointly-run university is proceeding in an orderly manner. The achievements have exceeded expectations and the first students will be welcomed in 2016. And in April this year, the two sides signed an important agreement on the establishment of the Moscow State University's Legal Aid Center for Chinese students. Therefore, in the face of the new opportunities for the development of regional cooperation between China and Russia, we should do following the basic principles of the common interests of both sides:

\section{A. Adhere to the Principle of Win-Win Cooperative Development}

Some our colleges and universities that have established contacts with Russian universities should fully use their own discipline advantages on the basis of existing research and development, and continuously strengthen and promote cooperation in scientific research and education between universities in the region. The setting professional courses and teaching research projects of planning and design must ensure realistic timeliness and serve as the focus of future research cooperation between China and Russia in the field of higher education. It is necessary to fully ensure that the key projects for exchanges and cooperation between the two parties meet the interests of both sides.

\section{B. Have An In-Depth Understanding of Each Other's National Contexts, So That You Know Yourself as well as the Other Party}

Under the conditions of common interest, the development of regional cooperation between universities in China and Russia is not a wish of one side but a major education project that requires both parties to jointly run and manage. This is because the regional cooperation between universities and the education cooperation project between regions are the common work of China and Russia. In this cooperation project, both China and Russia are the communities of interests from beginning to end. What China needs to do is to thoroughly understand the partner's specific conditions and fundamental realities of the country, including the Russian national policy on higher education, 
social sciences, humanities, and folk culture. At the same time, carrying out comprehensive research and analysis on all aspects is a necessity. Only by comprehensively, fully, exactly understanding and recognizing the basic national conditions of Russia, can we build a good foundation for regional cooperation between China and Russia's universities.

\section{Buildup of Regional Federation of Colleges and Universities}

The regional consortium of universities and colleges, including the Russian Far East and the higher education institutions in China, should be established, and the mutual aid relationship between the two sides should be strengthened while introducing high-quality educational resources. In accordance with the requirements of the actual development, China can put forward some proposals on the feasibility of both sides to Russia. At the same time, the association of colleges and universities can participate in the appraisal and evaluation work of the staff within the regional universities and colleges. Creating a new atmosphere for the regional cooperation between universities in China and Russia allows students from various universities to enjoy the professional teaching courses that they can learn in the information age environment. In this case, within the scope of regional cooperation, University students can no longer be restricted by regional conditions.

\section{Innovating the Regional Cooperation Mechanism of Chinese and Russian Universities and Deepening the Field of Cooperation}

We should innovate the regional cooperation mechanism of Chinese and Russian colleges and universities to diversify, enrich and systematize the cooperation mechanism. It is necessary to highlight the advantages of disciplines in universities in China and Russia, attract international students with high-quality and outstanding international courses, and enhance the competitiveness of national culture in international cooperation. It is necessary to highlight the concept of scientific collaborative innovation according to the needs of China's higher education professional disciplines and further deepen cooperation and exchanges in the academic field. The fund project is funded by "the academic backbone of the Heihe University" and "the backbone teachers of the Heihe University".

\section{CONCLUSION}

The educational exchanges between China and Russia have a long history. And it has good foundation for cooperation. However, the level of cooperation between the two countries is not high. And the people of the two countries lack the necessary cognition. Under the development of the common interests of China and Russia, the two countries can adhere to the development concept of mutual benefit and win-win cooperation, deepen the understanding of national conditions of each other, construct regional association of universities, innovate the mechanism of regional cooperation between the Chinese and Russian universities, and deepen the field of cooperation. The future regional cooperation between Chinese and Russian universities has broad prospects. The fund project is supported by the academic backbone of Heihe College and the backbone teachers of Heihe College.

\section{REFERENCES}

[1] Gu Wei. "The multi-layer analysis of the education cooperation between China and Russia" J. Journal of World Education, 2014(10).

[2] Yu Jiabin, Liu Xingfei. "Reflections on Sino-foreign Cooperation in Running Universities" J. Education Exploration, 2012(8).

[3] Li Huashu. "The concept innovation of regional cooperation and development of higher education in China -- with the perspective of the construction of European Higher Education Area" J. Sichuan University of Arts and Science Journal,2014(4).

[4] Wang Xiaojuan, Ke Mou. "Exploration of various ways of art exchange between China and Russia under the background of Sino Russian relations today" J. Popular Literature and Art, 2014(21).

[5] Liu Yujie. "The history and present situation of the exchanges and cooperation between China and Russia” J. Theory Research, 2013(12)

[6] Wang Changying, "An analysis of the international exchanges and cooperation between Chinese and Russian Colleges and Universities" J. Heilongjiang Researches on Higher Education, 2009(4).

[7] Chenyu Feng, "Reflections on China's cooperation in running a school with foreign colleges and universities" J. Education Exploration, 2011(1)

[8] Lili Qi, "The cultivation of College Students' innovation ability based on the mode of cooperatively running a school between China and Russia” J. China Market, 2017(7) 